\title{
Determination of Drilling Rate Index Based on Rock Strength Using Regression Analysis
}

\author{
HAYATI YENICE \\ Dokuz Eylül University, Mining Engineering Department, 35160, İzmir, Turkey \\ Manuscript received on October 25, 2018; accepted for publication on July 9, 2019
}

\begin{abstract}
How to cite: YENICE H. 2019. Determination of Drilling Rate Index Based on Rock Strength Using Regression Analysis. An Acad Bras Cienc 91: e20181095. DOI 10.1590/0001-3765201920181095.

Abstract: Drillability is influenced by many factors, including machine parameters and rock properties. The main machine parameters for drilling include rotational speed, thrust force, torque and flush pressure. The specific rock characteristics that affect penetration rate comprise uniaxial compressive strength (UCS), tensile strength, Young's modulus, hardness and brittleness. In this study, drilling rate index (DRI) is attempted to predict based on UCS and Brazilian tensile strength (BTS) of rocks. Simple and multiple regression analyses have been carried out to determine the best measure of the relation between DRI and two geomechanical properties. The DRI value is strongly related to the uniaxial compressive strength and indirect tensile strength. However, when the uniaxial compressive strength and tensile strength of rock are jointly considered, the correlation coefficient increases. The relationship between the geomechanical properties (UCS, BTS) and the DRI were determined using multiple regression analysis. Strong relationships were obtained from these analyses for the rock strength (UCS) above and below $100 \mathrm{MPa}$ with the correlation coefficients 0.81 and 0.88 respectively.The results of the regression analyses show that for more precise prediction of DRI, rocks should be classified according to their strength.
\end{abstract}

Key words: Drillability, uniaxial compressive strength, tensile strength, regression analysis.

\section{INTRODUCTION}

Drillability, one of the mostimportant considerations in rock excavation, can be defined as the ease of drilling a rock mass at a certain time to a certain length with a drilling bit. The drillability of rock is affected by numerous factors related to the drilling machine's working parameters and geotechnical characteristics of the rock mass. The machine parameters include the drilling method, bit types and shapes, and the technical features of the drilling rig used. The geotechnical parameters influence the drilling performance and the wear of bits and

E-mail: hayati.yenice@deu.edu.tr ORCid: https://orcid.org/0000-0001-9376-5915 include the condition and structure of rock mass and mechanical behaviour and mineral composition of rock materials. Therefore, when evaluating a rock mass from the point of view of its penetrability, qualitative and quantitative effects of the most important drilling parameters must be considered. Pandey et al. (1991) investigated the relationships between penetration rate values obtained from micro-bit drilling tests and compressive strength, tensile strength, shear strength and Protodyakonov strength index and found them to be logarithmic. Thuro (1996) reported unconfined compressive strength (UCS), Young's modulus and tensile strength as the rock properties frequently used in prediction of penetration rates. Kahraman (1999) 
developed a prediction model for down-the-hole and hydraulic drilling in open pit mines using regression analysis. This author determined UCS to be the dominant rock property for predicting performance of rotary and hydraulic top hammer drilling machines. He also found bit diameter, weight on bit and rotational speed as the most significant parameters affecting penetration rate in air-operated rotary drills that use tri-cone bits. Kahraman et al. (2000) developed a drillability index for predicting the penetration rate of rotary drills. The authors reported this drillability index to have a significant correlation with the proportionality constant $k$ and recommended the universal use of their proposed model for estimating the penetration rate of rotary blasthole drills. Altindag (2002) demonstrated the penetration rate to be closely related to rock brittleness. Bilgin and Kahraman (2003) correlated the net penetration rate of rotary blasthole drills with rock properties and found that the UCS, point load strength, Schmidt hammer (SH) value, Cerchar hardness and impact strength exhibit strong correlations with penetration rate. Kahraman et al. (2003) carried out a detailed investigation of the rock properties affecting penetration rate of percussive drills. The authors correlated penetration rate with rock properties and found UCS, tensile strength, point load strength and $\mathrm{SH}$ values to be the dominant rock properties affecting the penetration rates of percussive drills.

Hoseinie et al. (2009) proposed a classification system, called rock penetrability index (RPi), based on fuzzy Delphi analytic hierarchy process technique; this index is calculated based on UCS, Schimazek's $F$-abrasivity, Mohs hardness, texture, grain size and Young's modulus of rocks. The authors showed that RPi can be used to predict penetration rates. Yenice et al. (2009a-b) correlated drilling rate index (DRI) with mechanical rock properties of marble samples and determined a strong relationship between DRI and UCS, tensile strength and specific destruction energy. Yaşar et al. (2011) conducted a laboratory study on cement mortar samples to investigate the influence of operational parameters on rock drillability. The authors found strong correlations between penetration rates, specific energies and UCSs of the samples. Yarali and Kahraman (2011) studied the effect of brittleness on drillability of 32 rock types. They correlated these brittleness values with DRI values and determined that brittleness values obtained using the equation suggested by Altindag (2000) can be used in assessment of rock drillability. Alireza et al. (2012) proposed a model called the Specific Rock Mass Drillability (SRMD) index for predicting the penetration rate of rotary drills. They correlated SRMD with various rock properties and concluded UCS and SH values as the most significant factors.

Yarali and Soyer (2013) examined the relationship between the DRI and various rock properties and found decreasing linear relationships between the DRI and UCS, SH, Shore scleroscope hardness (SSH) and point load strength.

Saeidi et al. (2014) used principal component analysis to develop a penetration rate model for rotary drilling, which is based on the weight on bit, rotational speed, joint dipping, joint spacing, bit diameter and UCS of rocks. In a sensitivity analysis, the authors found the UCS of rock, weight on bit and bit rotational speed to be the most significant parameters.

Özfirat et al. (2016) proposed a new brittleness index for predicting the DRI using UCS and tensile strength. Yetkin et al. (2016) investigated the relationships among DRI, rock cutting index and some strength properties of rocks. They suggested that DRI and strength properties can be reliably used for predicting cutting machine performance.

This study is applied to rocks coming from different locations in Turkey and the world. According to test results, multivariable functions are derived to estimate DRI for rocks featuring UCS above and below $100 \mathrm{MPa}$. 


\section{LABORATORY STUDIES}

In this study standard test samples were prepared from rock blocks and core samples which were collected from the field for laboratory tests. Uniaxial compressive strength, Brazilian tensile strength and drillability tests were carried out on 31 different rock samples. The summaries of the test results are given in Table I.

\section{DETERMINATION OF DRI}

DRI is a measure of the difficulty or ease of drilling rock, and it was developed at the Norwegian University of Science and Technology in Trondheim, Norway. DRI is based on results of two laboratory tests - brittleness test $\left(\mathrm{S}_{20}\right)$ and Sievers'J (SJ)-miniature drill test (Bruland 1998).

Sievers'J-miniature drill test, developed by H. Sievers in the 1950s, indirectly measures the surface hardness of rocks (Dahl 2003). Sievers'J value is obtained in a miniature drill test (Figure 1) by measuring the hole depth in a rock sample after 175-200 revolutions of drill bit in $1 / 10 \mathrm{~mm}$. The test is repeated four to eight times for each rock sample, and Sievers'J value is the mean value of measured test-hole depths.

Brittleness value, $\mathrm{S}_{20}$, is an indirect measure of rock resistance to crack growth and crushing by repeated impacts (Figure 2). This test, developed by N. von Matern and A. Hjelmer in 1943 (Dahl 2003), is performed in three equal extractions in 11.2-16.0 $\mathrm{mm}$ fraction. The aggregate volume of rock sample corresponds to that of a $500 \mathrm{~g}$ aggregate with a density of $2.65 \mathrm{~g} / \mathrm{cm}^{3}$ in the $11.2-16.0-\mathrm{mm}$ fraction (Puhakka 1997). Brittleness value is calculated as the percentage of undersized material that passes through an $11.2 \mathrm{~mm}$ mesh after 20 drops of a $14 \mathrm{~kg}$ hammer and is presented as the mean value of three or four parallel tests.

The diagram shown in Figure 3 shows how DRI is determined based on brittleness $\mathrm{S}_{20}$ and Sievers'J values (Dahl 2003).

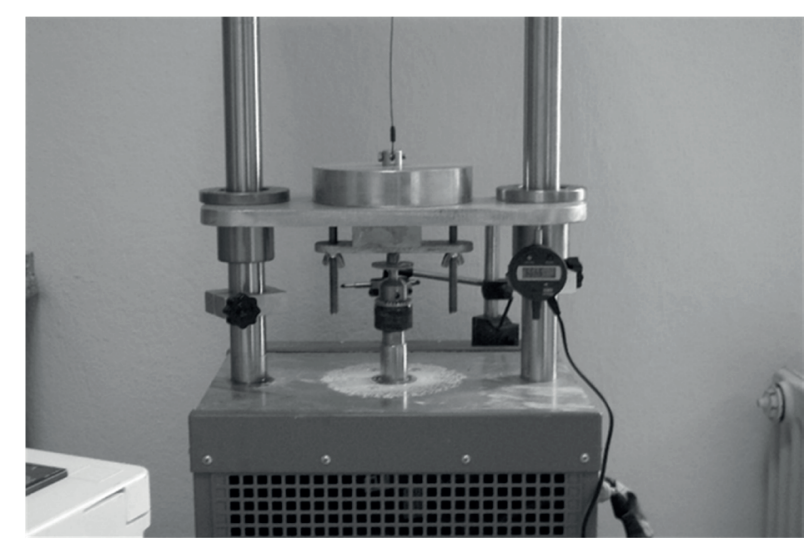

Figure 1 - Sievers'J-miniature drill test apparatus.

UCS TEST AND BRAZILIAN TENSILE STRENGTH (BTS)

The UCS and BTS tests have been conducted according to the standards suggested by the International Society for Rock Mechanics (ISRM) (Ulusay and Hudson 2007). Uniaxial compression tests were carried out on trimmed cylindrical core samples, having a length-to-diameter ratio of 2.0 2.5. The samples are loaded with a loading rate of $0.5-1.0 \mathrm{MPa} / \mathrm{s}$.

BTS tests were performed on core samples with a thickness-to-diameter ratio of 0.5 . The tests have been repeated for each rock type at a loading rate of $20 \mathrm{kgf} / \mathrm{s}$, and average of the test results were recorded as the tensile strength value.

\section{STATISTICAL ANALYSIS}

Regression analysis is a type of statistical evaluation that enables the description of relationships among the dependent (response) variables and the independent (regressor) variables, and estimation of the values of the dependent variables from the observed values of the independent variables.

Linear regression methods are appropriate when the relationship between the dependent variables and independent variables can be built linearly. In this study, both simple linear and multiple linear regression models were used to describe the relations between the DRI and the rock strength, UCS and BTS. 

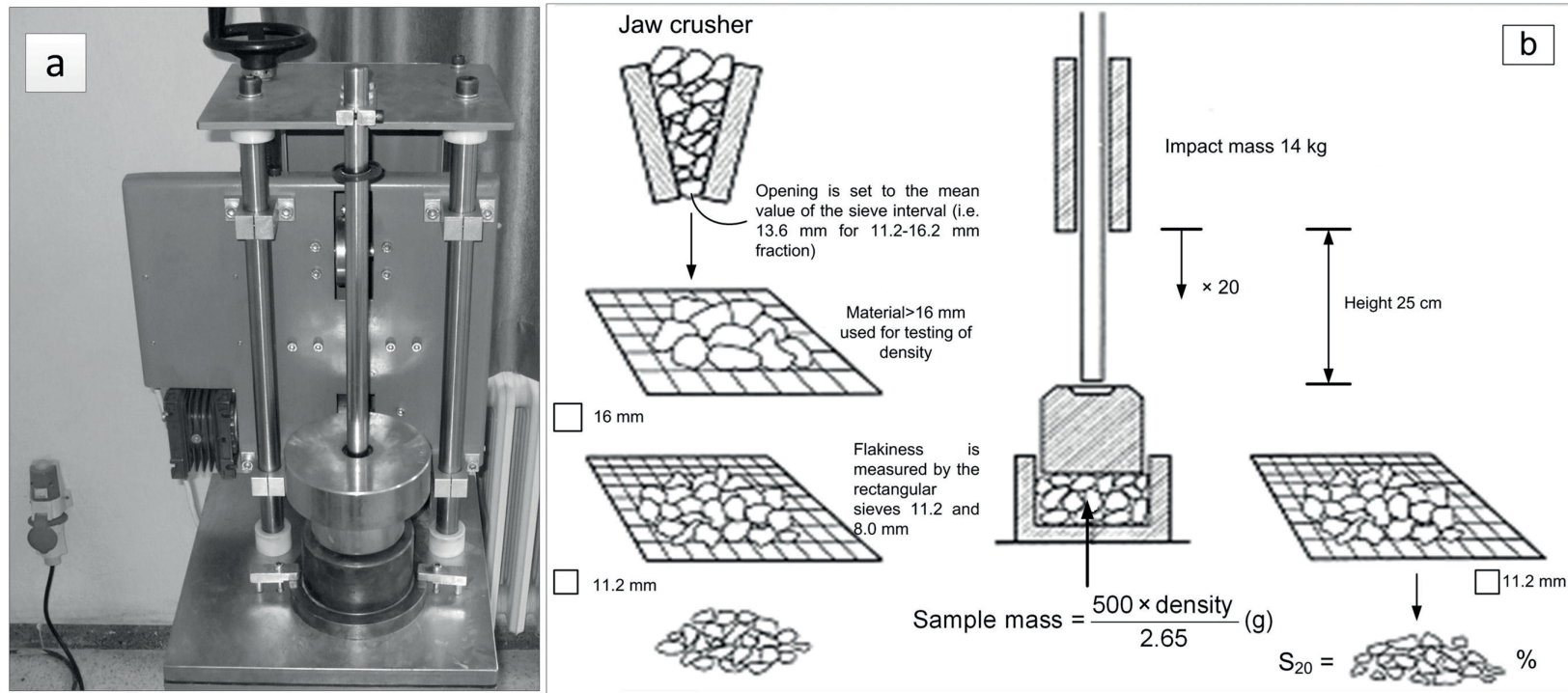

Figure 2 - a) Brittleness test apparatus; b) Scheme of brittleness test (Dahl 2003).

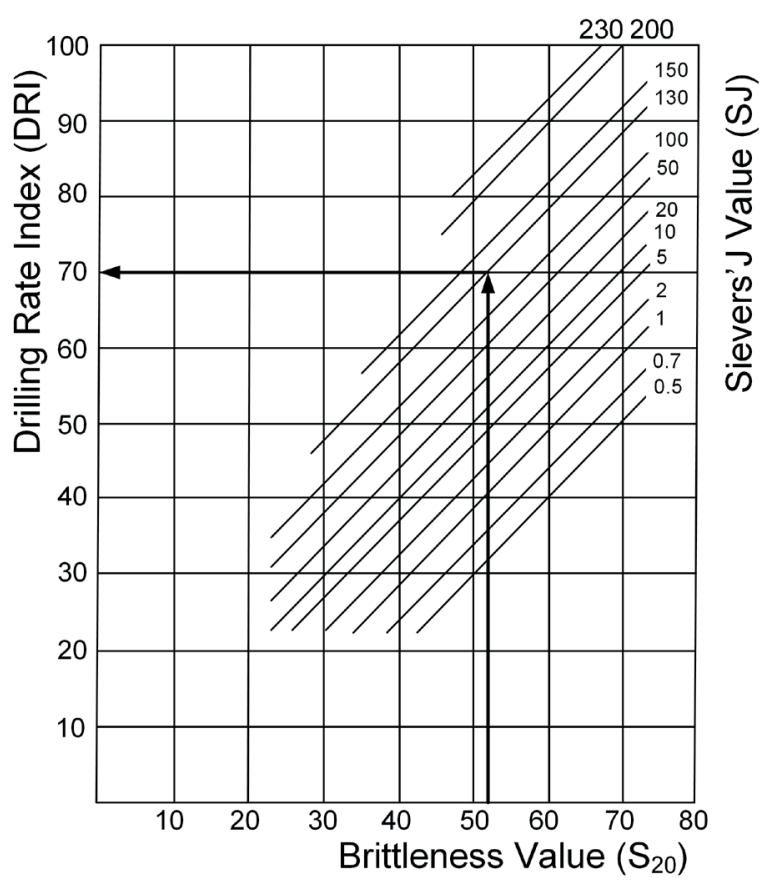

Figure 3 - Diagram of DRI assessment (Dahl 2003).

SIGMAPLOT 11.0 software has been used for statistical evaluations. The independent samples t-test and one way ANOVA has been used to analyze and interpret the data.

Statistical evaluations were carried out in two stages. In the first stage, test results are evaluated without any classification. The results of first analysis shows that it is good to classify the data according to UCS values. In the second stage, simple and multiple linear regression analyses were performed for estimating the DRI values of rocks with UCS values above and below $100 \mathrm{MPa}$.

The function (Equation 1) between UCS and DRI was determined using statistical analysis. As given in Figure 4a, it can be seen that there is no linear relationship between the UCS and DRI $(\mathrm{R}=0.33)$.

$D R I=66.43-0.09006 U C S$

$\mathrm{S}=12.266 \quad \mathrm{R}-\mathrm{Sq}=11.0 \% \mathrm{R}-\mathrm{Sq}_{(\mathrm{adj})}=7.9 \%$

By means of statistical analysis of BTS and DRI, the function (Equation 2) was obtained that defines the relation between the BTS and DRI values. The function was derived using the least squares method. As seen in Figure 4b, the low $\mathrm{R}(0.588)$ value means that there is no linear relationship between BTS and DRI.

$D R I=80.26-2.894 B T S$

$\mathrm{S}=10.510 \mathrm{R}-\mathrm{Sq}=34.6 \% \mathrm{R}-\mathrm{Sq}(\operatorname{adj})=32.4 \%$

Multiple regression analysis was also performed for the unsorted data to determine the predictability of the DRI based on UCS and BTS 
TABLE I

UCS, Brazilian Tensile Strength (BTS) and DRI values.

\begin{tabular}{|c|c|c|c|c|c|c|c|}
\hline & Sample Code & $\begin{array}{c}\text { Sample } \\
\text { Location }\end{array}$ & UCS (MPa) & BTS (MPa) & $\begin{array}{l}\text { Brittleness } \\
\text { Value }\left(S_{20}\right)\end{array}$ & $\begin{array}{l}\text { Sievers' J } \\
\text { Value }\left(S_{j}\right)\end{array}$ & DRI \\
\hline \multirow{11}{*}{ 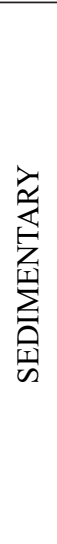 } & L1 & Soma & 59.25 & 4.26 & 60.00 & 80.00 & 71 \\
\hline & L2 & Antalya & 61.60 & 7.20 & 50.86 & 52.10 & 58 \\
\hline & L3 & İzmir & 64.61 & 5.43 & 50.76 & 59.80 & 59 \\
\hline & $\mathrm{L} 4$ & Denizli & 69.20 & 6.95 & 41.25 & 40.50 & 47 \\
\hline & L5 & Denizli & 77.80 & 8.60 & 37.52 & 35.10 & 43 \\
\hline & L6 & Denizli & 73.40 & 7.70 & 40.11 & 42.50 & 47 \\
\hline & L7 & Soma & 91.55 & 5.50 & 36.70 & 81.00 & 47 \\
\hline & L8 & Soma & 116.00 & 9.10 & 60.00 & 53.00 & 69 \\
\hline & L9 & Soma & 128.91 & 8.67 & 55.32 & 87.00 & 66 \\
\hline & L10 & Soma & 151.07 & 9.26 & 52.76 & 63.00 & 63 \\
\hline & L11 & Soma & 88.33 & 7.08 & 48.20 & 51.00 & 56 \\
\hline \multirow{13}{*}{ 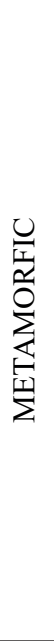 } & KW & Aydın & 23.43 & 3.61 & 82.83 & 52.30 & 89 \\
\hline & YW & Mugla & 45.67 & 5.40 & 58.44 & 52.50 & 67 \\
\hline & $\mathrm{BB}$ & İzmir & 52.74 & 8.69 & 44.91 & 82.60 & 55 \\
\hline & AW & Afyon & 57.66 & 6.57 & 54.38 & 85.20 & 65 \\
\hline & G & Afyon & 82.00 & 9.10 & 37.20 & 41.00 & 45 \\
\hline & B & Burdur & 83.20 & 11.80 & 37.86 & 41.00 & 45 \\
\hline & K & Mugla & 75.50 & 9.30 & 35.36 & 30.80 & 42 \\
\hline & ES & Mugla & 110.39 & 10.06 & 46.85 & 41.00 & 54 \\
\hline & MFB & Mugla & 134.72 & 5.72 & 50.43 & 50.20 & 59 \\
\hline & MFK & Mugla & 149.87 & 6.22 & 53.64 & 55.40 & 62 \\
\hline & MFR & Mugla & 169.89 & 6.75 & 51.52 & 48.10 & 60 \\
\hline & $\mathrm{F}$ & Aydin & 51.00 & 3.28 & 77.15 & 41.23 & 83 \\
\hline & $\mathrm{G}$ & Aydin & 55.32 & 5.96 & 48.19 & 16.11 & 49 \\
\hline \multirow{7}{*}{ 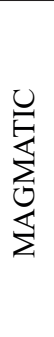 } & G1 & Spain & 118.00 & 8.00 & 69.23 & 5.60 & 68 \\
\hline & G2 & Giresun & 131.50 & 11.20 & 64.93 & 10.70 & 67 \\
\hline & G3 & Italy & 156.00 & 9.50 & 61.97 & 9.00 & 62 \\
\hline & G4 & İzmir & 177.80 & 7.66 & 50.32 & 7.20 & 48 \\
\hline & G5 & İzmir & 112.00 & 10.50 & 55.87 & 10.80 & 57 \\
\hline & G6 & Norway & 182.00 & 13.50 & 52.16 & 3.60 & 47 \\
\hline & Basalt & İzmir & 206.40 & 13.82 & 30.02 & 3.80 & 25 \\
\hline
\end{tabular}

values. The analysis results for DRI versus UCS and BTS indicate that there is no linear relationship in either case $(\mathrm{R}=0.588$, Rsqr $=0.3467)$. The adjusted $\mathrm{R}$ square value indicates that this model (Equation 3) accounts for $30.01 \%$ of variance in the DRI, but no significance model (Table II, Figure 5).

$D R I=80.13-0.0078 U C S-2.978 B T S$

\section{REGRESSION ANALYSIS FOR UCS} VALUES ABOVE 100MPA

After classifying the data according to UCS values, simple linear regression analysis was performed for UCS values, which are higher than $100 \mathrm{MPa}$, versus DRI and obtained a functional relation (Equation 4). As shown in Figure 6a, the high 


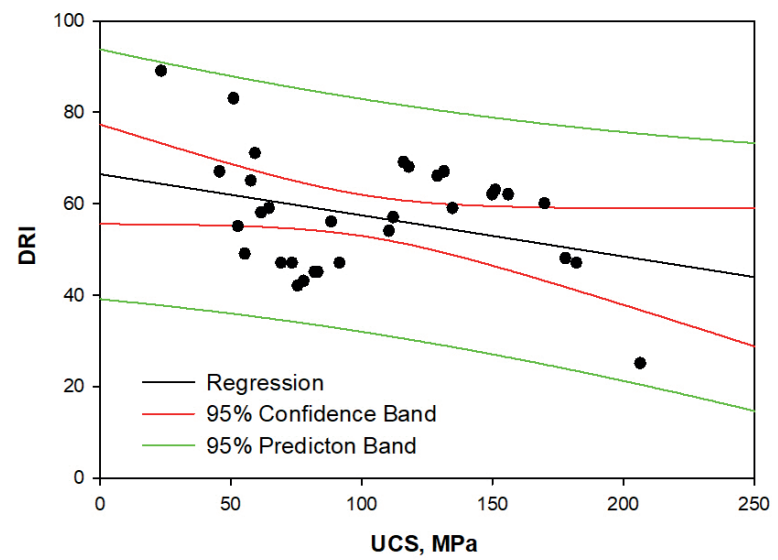

(a)

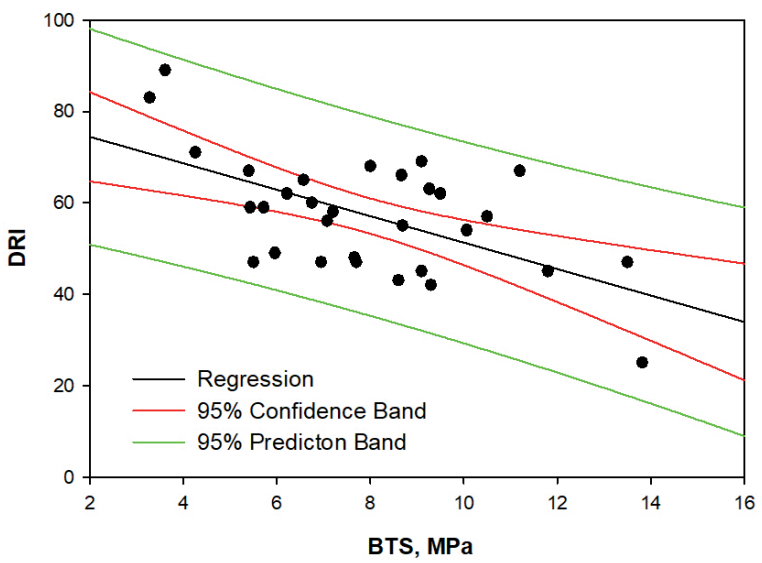

(b)

Figure 4 - Relations between DRI versus UCS (a) and BTS (b).

TABLE II

Analysis of variance for the model with two parameters (UCS, BTS).

\begin{tabular}{cccccc}
\hline Source & DF & Adj SS & Adj MS & F-Value & P-Value \\
\hline Regression & 2 & 1698.98 & 849.49 & 7.43 & 0.003 \\
UCS (MPa) & 1 & 2.60 & 2.60 & 0.02 & 0.881 \\
BTS & 1 & 1162.35 & 1162.35 & 10.17 & 0.004 \\
Error & 28 & 3200.95 & & & \\
Total & 30 & 4899.94 & & & \\
\hline
\end{tabular}

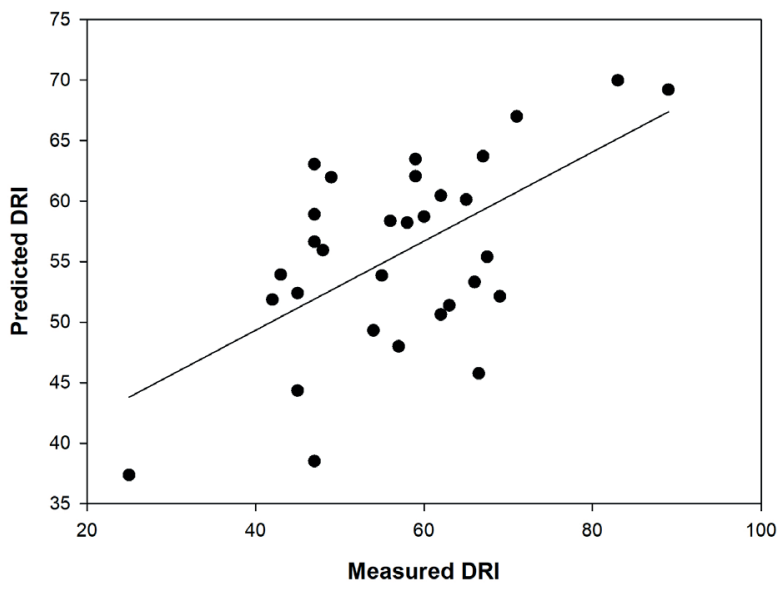

Figure 5 - DRI versus predicted DRI values for the regression model with UCS and BTS.

$R(0.736)$ value indicates that there is a positive relationship between the DRI and UCS.

$D R I=99.44-0.287 U C S$

$\mathrm{S}=8.185 \mathrm{R}-\mathrm{Sq}=54 \% \mathrm{R}-\mathrm{Sq}_{(\mathrm{adj})}=50.02 \%$
Simple linear regression analysis was also carried out for BTS values versus DRI, and obtained a relationship given below is obtained;

$D R I=82.43-2.678 B T S$

$\mathrm{S}=9.913$

$$
\mathrm{R}-\mathrm{Sq}=32 \% \mathrm{R}-\mathrm{Sq}_{(\mathrm{adj})}=26.3 \%
$$

As shown in Figure 6b, the low $\mathrm{R}(0.56)$ value indicates that there is no significant relationship between the DRI and BTS for this group.

A second multiple regression analysis was performed for UCS and BTS versus DRI. The significance of this model was noted by citing the $\mathrm{R}$ (0.812) and $R$ square (0.660) values, which show the strength of the model. For the final results, one can say that the $\mathrm{F}_{\mathrm{c}}$ ratio (in the ANOVA results shown in Table III) is 10.71 and is significant at $\mathrm{p}<0.001$. The $\mathrm{F}_{\mathrm{t}}$ ratio from the F-Distribution Table (for $\alpha=$ $0.05)$ is 3.98. The $F_{t}<F_{c}$ and $p<0.05$ result shows 


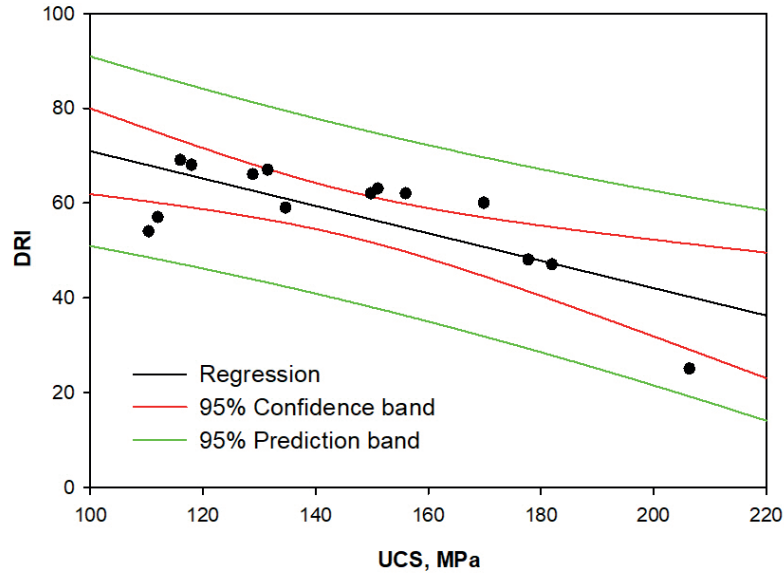

(a)

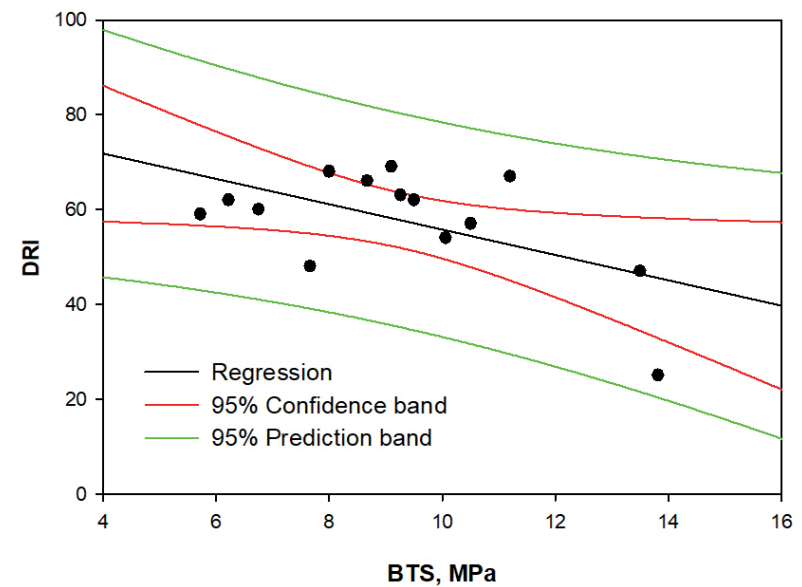

(b)

Figure 6 - Relations between DRI versus UCS (a) and BTS (b) (for UCS $>100 \mathrm{MPa}$ ).

TABLE III

Analysis of variance for the model with two parameters (UCS, BTS).

\begin{tabular}{|c|c|c|c|c|c|}
\hline Source & DF & Adj SS & Adj MS & F-Value & P-Value \\
\hline Regression & 2 & 1158.3 & 579.15 & 10.71 & 0.003 \\
\hline UCS (MPa) & 1 & 605.3 & 605.33 & 11.19 & 0.007 \\
\hline BTS & 1 & 208.9 & 208.93 & 3.86 & 0.075 \\
\hline Error & 11 & 594.9 & 54.08 & & \\
\hline Total & 13 & 1753.2 & & & \\
\hline
\end{tabular}

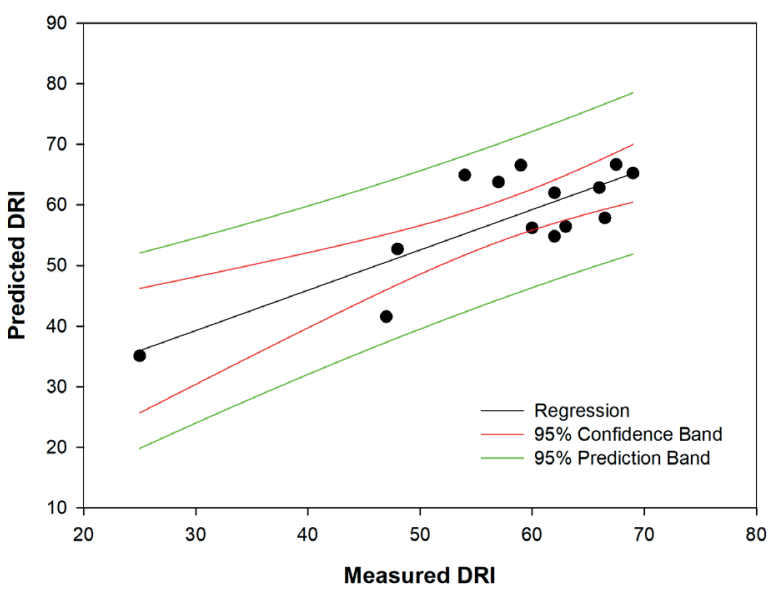

Figure 7 - DRI versus predicted DRI values for the regression model with UCS and BTS (for UCS $>100 \mathrm{MPa}$ ).

that the null $\left(\mathrm{H}_{0}\right)$ hypothesis is rejected. This yields a strong proof for a linear relationship (Equation 6) between the response (DRI) and the two explanatory variables (BTS and UCS, Figure 7).

$D R I=109.2-0.2430 U C S-1.734 B T S$
$\mathrm{S}=7.35 \mathrm{R}-\mathrm{sq}=66.07 \% \mathrm{R}-\mathrm{sq}(\operatorname{adj})=59.90 \%$

$\mathrm{R}-\mathrm{sq}($ pred $)=30.87 \%$

\section{REGRESSION ANALYSIS FOR UCS VALUES BELOW 100MPa}

In the statistical analysis of DRI and UCS, the formula (Equation 7) was obtained that defines the relation between the DRI and UCS values which are below $100 \mathrm{MPa}$. The formula was derived using the least squares method, as shown in Figure 8a. As it can be seen from the plot, the high value (0.793) of $\mathrm{R}$ is consistent with the positive relationship between the DRI and UCS. Figure $8 \mathrm{~b}$ shows the relation between DRI and BTS for the same group. Equation (8) defines the relationship between DRI and BTS for the samples having UCS below100 $\mathrm{MPa}$. The high $\mathrm{R}(0.784)$ value shows that there is a strong correlation between two groups. 


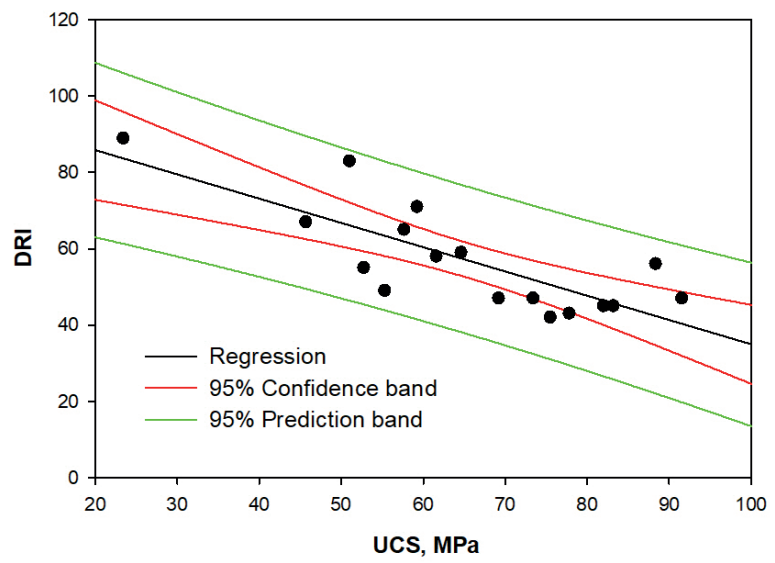

(a)

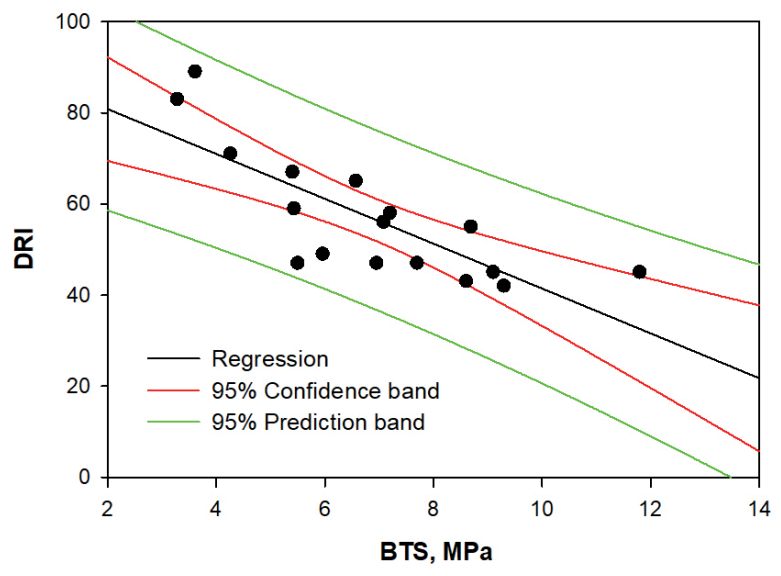

(b)

Figure 8 - Relations between DRI versus UCS (a) and BTS (b) (for UCS $<100 \mathrm{MPa}$ ).

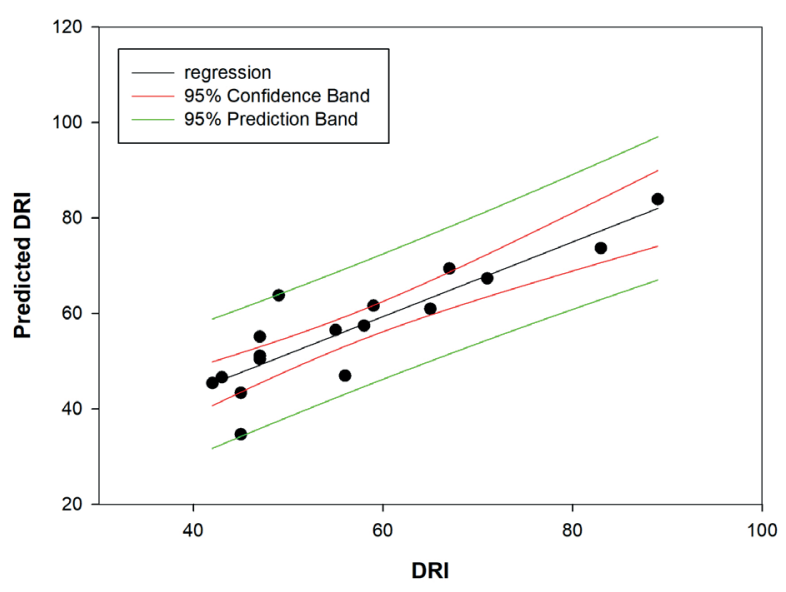

Figure 9 - DRI versus predicted DRI values for the regression model with UCS and BTS (for UCS $<100 \mathrm{MPa}$ ).

$D R I=98.63-0.6372 U C S$

$\mathrm{S}=8.817 \mathrm{R}-\mathrm{Sq}=62.9 \% \mathrm{R}-\mathrm{Sq}(\operatorname{adj})=60.4 \%$

$D R I=90.67-4.925 B T S$

$S=8.983$

$$
\mathrm{R}-\mathrm{Sq}=61.5 \% \mathrm{R}-\mathrm{Sq}(\operatorname{adj})=58.9 \%
$$

A third multiple regression analysis was carried out for the prediction of the DRI based on the BTS and UCS values, and the results of the regression are given in Table IV. According to our multiple regression analysis, the BTS versus DRI and the
UCS versus DRI results indicate that there may be a linear relationship (Equation 9$)(\mathrm{R}=0.884$, $\mathrm{Rsqr}=$ 0.781 ). The adjusted $R$ square value shows that this model attributes for $78.15 \%$ of the variance in the DRI, which is significant. In Table IV, when $\mathrm{df}_{1}=2$ and $\mathrm{df}_{2}=14$, the Ft-value from the F-Distribution Table (for $\alpha=0.05$ ) decreases to 3.74, whereas the calculated $\mathrm{Fc}$ value is 25.04. In other words, $\mathrm{F}_{\mathrm{t}}$ is significantly smaller than $\mathrm{F}_{\mathrm{c}}$. Additionally, the $\mathrm{P}$-value is smaller than 0.05 , which supports the proof for a linear relationship between the DRI and the two explanatory variables. As a consequence the multiple regression equation used to determine the results given in Table IV, can be used for the prediction of DRI (Figure 9).

$D R I=104.40-0.407 U C S-3.043$ BTS

$S=7.0$ R-sq $=78.15 \%$ R-sq(adj) $75.03 \%$

$\mathrm{R}-\mathrm{sq}(\mathrm{pred})=64.91 \%$

\section{RESULTS AND DISCUSSION}

Drillability of a rock is affected by many different factors, such as drilling machine parameters and geotechnical characteristics of rock mass. Especially, condition and structure of rock mass, 
TABLE IV

Analysis of variance for the model with two parameters (UCS, BTS).

\begin{tabular}{cccccc}
\hline Source & DF & Adj SS & Adj MS & F-Value & P-Value \\
\hline Regression & 2 & 2456.3 & 1228.13 & 25.04 & 0.000 \\
UCS (MPa) & 1 & 523.6 & 523.65 & 479.68 & 0.006 \\
BTS & 1 & 479.4 & 49.05 & 9.77 & 0.007 \\
Error & 14 & 686.7 & & \\
Total & 16 & 3142.9 & & \\
\hline
\end{tabular}

mechanical behaviour and mineral composition of rock material are the main characteristics affecting drillability. Pandey et al. (1991), Wijk (1991), Thuro (1996), Kahraman (1999), Altındag (2002), Kahraman et al. (2003), Yaşar et al. (2011), Alireza et al. (2012), Yaralı and Soyer (2013) and Saeidi et al. (2014) investigated the relations between penetration rate values obtained from drilling tests and compressive strength, tensile strength, shear strength and Protodyakonov index and observed logarithmic relationships. However, in this study, motivation and contribution differ from those of previous studies. In the present study, regression analysis is used to estimate DRI values of rock according to UCS and BTS values. Simple and multivariable functions were determined by using regression analysis for rocks classified according to their strength. Multivariable functions are understandable, suitable and economic for predicting DRI values of rocks. These functions and results are useful for mine practitioners, especially for drilling, cutting and other rock field operations.

\section{CONCLUSIONS}

DRI test is commonly used to predict performances of underground excavation machines. To determine this index value, Sievers'J-miniature drill test and brittleness $\left(\mathrm{S}_{20}\right)$ test are carried out. These tests, on the other hand, require extremely long periods because of laborious size reduction and sieving efforts and cause an increase in consumption of drill bits.

In this study, correlations between the DRI and two geomechanical properties of rocks were investigated. Using simple and multiple regression analyses, the degree was determined to which DRI values can be estimated based on rock strength. The results were profoundly discussed in the following paragraphs.

According to first simple and multiple regression analysis, the rocks should be classified according to their strength so that the analysis is to estimate the relations more precisely. In the case of simple and multiple regression analyses that rocks were classified according to their strength, linear relations with different correlation coefficients have been obtained in cases where strength is above and below 100MPa.

Based on simple regression analysis, it was found that DRI has a strong $(\mathrm{R}=0.73)$ relation with the UCS for the rocks with strength above $100 \mathrm{MPa}$. For the rocks having a strength lower than $100 \mathrm{MPa}$, it was also found a more strong relationship between DRI and UCS with a correlation coefficient of 0.79 .

A relationship between the geomechanical properties (UCS, BTS) and the DRI was determined using multiple regression analysis. Strong relationships were obtained from these analyses for the rock strength above and below 100MPa with the correlation coefficients 0.81 and 0.88 respectively.

As a result of regression analysis, estimating DRI values yield better results by classifying rocks according to UCS values.

\section{REFERENCES}

ALIREZA C, SEYED HK, KOUROSH S AND JAFAR KH. 2012. An estimation of the penetration rate of rotary drills 
using the Specific Rock Mass Drillability index. Int J Min Sci Technol 22: 187-193.

ALTINDAG R. 2000. The role of rock brittleness on the analysis of percussive drilling performance. In: Proceedings of $5^{\text {th }}$ Turkish national rock mechanics symposium, Isparta, Turkey, p. 105-112.

ALTINDAG R. 2002. The evaluation of rock brittleness concept on rotary blast hole drills. J S Afr I Min Metall 102(1): 61-66.

BILGIN N AND KAHRAMAN S. 2003. Drillability prediction in rotary blast hole drilling. $18^{\text {th }}$ International Mining Congress and Exhibition of Turkey-IMCET 2003, p. 177-182.

BRULAND A. 1998. Project report 13A-98-Hard rock tunnel boring: Drillability Test methods, 22 p., NTNU Trondheim.

DAHL F. 2003. DRI, BWI, CLI Standards. NTNU, Angleggsdrift, Trondheim, $21 \mathrm{p}$.

HOSEINIE SH, ATAEI M AND OSANLOO M. 2009. A new classification system for evaluating rock penetrability. Int J Rock Mech Min Sci 46: 1329-1340.

KAHRAMAN S. 1999. Rotary and percussive drilling prediction using regression analysis. Technical Note, Int J Rock Mech Min Sci 36: 981-989.

KAHRAMAN S, BALCI C, YAZICI S AND BILGIN N. 2000. Prediction of the penetration rate of rotary blast hole drills using a new drillability index. Int J Rock Mech Min Sci 37: 729-743.

KAHRAMAN S, BILGIN N AND FERIDUNOGLU C. 2003. Dominant rock properties affecting penetration rate of percussive drills. Int J Rock Mech Min Sci 40: 711-723.

ÖZFIRAT MK, YENICE H, ŞIMŞIR F AND YARALI O. 2016. A new approach to rock brittleness and its usability at prediction of drillability. J Afr Earth Sci 119(2016): 94101.

PANDEY AK, JAIN AK AND SINGH DP. 1991. An investigation into rock drilling. Int J Min Reclam Env 5: 135-141.
PUHAKKA T. 1997. Underground drilling and loading handbook. Tamrock Corp, Finland, 271 p.

SAEIDI O, TORABI S R, ATAEI M AND ROSTAMI J. 2014. A stochastic penetration rate model for rotary drilling in surface mines. Int J Rock Mech Min Sci 68: 55-65.

THURO K. 1996. Drillability prediction in hard rock tunneling. In: Conference On Prediction In Geology, Vrije Üniversiteit, Amsterdam.

ULUSAY R AND HUDSON JA. 2007. The Blue Book: The Complete ISRM Suggested Methods for Rock Characterization, Testing and Monitoring: 1974-2006. ISRM Turkish National Group, Ankara, 628 p.

WIJK G. 1991. Rotary drilling prediction. Int J Rock Mech Min Sci Geomech Abstr 28(1): 35-42.

YARALI O AND KAHRAMAN S. 2011. The drillability assessment of rocks using the different brittleness values. Tunn Undergr Sp Tech 26: 406-414.

YARALI O AND SOYER E. 2013. Assessment of relationships between drilling rate index and mechanical properties of rocks. Tunn Undergr Sp Tech 33: 46-53.

YAŞAR E, RANJITH PG AND VIETE DR. 2011. An experimental investigation into the drilling and physicomechanical properties of a rock like brittle material. J Petrol Sci Eng 76: 185-193.

YENICE H, ÖZFIRAT MK, KARACA Z AND KAHRAMAN B. 2009a. Investigation of the parameters effecting Drilling Rate Index (DRI) of Marbles. In: Proceedings of the $2^{\text {nd }}$ Mining Machinery Symposium of Turkey, 4-6 November, Zonguldak, Turkey, p. 233-246.

YENICE H, ÖZFIRAT MK, KAHRAMAN B, ÖZDOGAN MV. 2009bb. Examination of Drilling Rate Index (DRI) of Rocks. In: Proceedings of the $3^{\text {rd }}$ Balkan Mining Congress, 1-3 October, Izmir, Turkey, p. 321-328.

YETKIN ME, ÖZFIRAT MK, YENICE H, ŞIMŞIR F AND KAHRAMAN B. 2016. Examining the relation between rock mass cuttability index and rock drilling properties. J Afr Earth Sci 124(2016): 151-158. 